\title{
CORRECTION
}

\section{Correction to: Research on the Influence of Spacer Ring on the Sealing Performance of Packing Element used in Compression Packer}

\author{
Gang Hu $\cdot$ Mingcheng Wang $\cdot$ Guorong Wang $\cdot$ Xia He
}

Published online: 28 October 2021

(C) ASM International 2021

Correction to: J Fail. Anal. and Preven. https://doi.org/10.1007/s11668-021-01209-4

The original online version of this article was corrected.

Figures 27, 28, and 29 have been updated.

The original article can be found online at https://doi.org/10.1007/ s11668-021-01209-4.

G. Hu $(\bowtie) \cdot$ M. Wang $\cdot$ G. Wang $\cdot$ X. He

School of Mechatronic Engineering, Southwest Petroleum

University, Chengdu 610500, China

e-mail: swpu_hugang@163.com

G. Wang

Energy Equipment Institute, Southwest Petroleum University,

Chengdu 610500, China
Publisher's Note Springer Nature remains neutral with regard to jurisdictional claims in published maps and institutional affiliations. 